\title{
Ernest Marcus
}

\section{ERASMO GARCIA MENDES}

$\mathrm{E}$

rnst Gustav Gotthelf Marcus nasceu em Berlim, em 1893, de progenitores judeus inteiramente identificados com os costumes e a cultura da Alemanha imperial. O pai era jurista e o filho pode seguir o caminho normal de qualquer outro cidadáo do país, compartilhando seus ideais, aspirações e destino. Eclodida a Primeira Guerra Mundial, Marcus dela participou como soldado, combatendo nas frentes oriental e ocidental e, se não me engano, foi condecorado. Em 1914, logo no ano do início da guerra, Marcus publicou seu primeiro trabalho zoológico; o segundo, devido ao conflito, só apareceu em 1919. Já estava entáo na Universidade de Berlim, onde começava sua carreira docente no Instituto de Zoologia, e teve o privilégio de conviver com os grandes mestres Heider e Hesse. $O$ primeiro era embriologista experimental e o segundo autor de dois clássicos da literatura zoológica (Tierbau und Tierleben, Tiergeographie auf oekologiscgher Grundlage). Os dois exerceram grande influência sobre Marcus. Heider despertou nele uma perene paixão pela Entwicklungsmekanik, disciplina que Marcus ministrou durante largos anos em São Paulo, como Mecanica do Desenvolvimento, pondo seus alunos em contato com as obras de Roux, Spemann, Mangold, Driesch e Harrison. Admirava Driesch, sobretudo, por ter acabado por conceituar a embriologia em termos de enteléquia.

Marcus teve a felicidade de se casar com Eveline Du Bois Reymond, de tradicional família de cientistas, neta do grande Emil Du Bois Reymond (um dos modeladores da fisiologia moderna) e uma excelente desenhista. Em colaboraçăo, realizaram prodigiosa obra zoológica (Marcus, no Brasil, frequientemente iniciava seus artigos mencionando: "Com minha excelentíssima esposa..." ). Ainda na Alemanha, após ter trabalhado com coleópteros, investigou grupos menos conhecidos de animais, como Bryozoa e Tardigrada, grangeando grande reputação, num total de 53 trabalhos, até 1933. Escreveu o volume sobre Tardigrada na coleção Bronn's Klassen und Ordnungen des Tierreiches e estudou a embriogênese da boca e do intestino anterior de peixes selácios e anfíbios anuros. Ainda em 1933, publicou uma Tiergeographie, na qual seus amplos conhecimentos das faunas regionais em contexto ecológico ficaram patentes.

Como a situação dos judeus foi se tornando cada vez mais insuportável após o advento do Nazismo, Marcus acabou aceitando o con- 
vite feito para lecionar zoologia na Faculdade de Filosofia da Universidade de São Paulo, em substituição ao professor da disciplina anteriormente contratado, o notável Ernst Bresslau, falecido repentinamente em 1935. Marcus chegou ao Brasil em I de abril de 1936, acompanhado da esposa e livros que lhe permitiram trazer de Alemanha.

Tive o privilégio de assistir, como aluno, à primeira aula dada por Marcus no país, proferida no laboratório do Departamento de Parasitologia da Faculdade de Medicina, onde o Departamento de Zoologia se instalara antes da mudança para a alameda Glette. A aula foi dada em português, língua que aprendera suficientemente no curto tempo de que dispusera antes de partir de Berlim. Esse português foi continuamente aperfeiçoado com os anos, a ponto de empregar, nas aulas, termos tão eruditos que muitos alunos tinham dificuldade de entender. Dizia que o seu conhecimento do latim ajudava-o no português. A mim chegou a corrigir, várias vezes, quando incidia em erros flagrantes para ele. Esse seu rigor no falar (e no escrever) motivou pelo menos um episódio pitoresco. Estando Marcus aguardando conduçăo na esquina da Glette com Sáo João, foi interpelado por um transeunte sobre se certo bonde ia prá cidade, quando perguntou ao mesmo qual o conceito que fazia de cidade pois, para ele, cidade era São Paulo inteira, enquanto que para o interpelante significava, na época, o Centro da mesma. Nessa sua primeira aula, dada um dia após sua chegada ao Brasil, Marcus trajava um fato cinzento, de corte moderno, um dos dois que trouxera da Alemanha; o outro, preto, de uso costumeiro, tinha um talhe avant guerre, dando-lhe um ar circunspecto de velho professor universitário alemão, quando tinha apenas $\mathbf{4 3}$ anos.

Durante 37 anos, até a aposentadoria compulsória, ministrou aulas de zoologia, sem nunca faltar e com acurado preparo das mesmas. Sua última aula foi em 7 de junho de 1963, na qual concluiu o estudo dos Aschelminthes e iniciou o dos Annelida. Suas aulas eram dadas em nível elevadíssimo e, na verdade, era desperdício colocá-lo ensinando zoologia básica, que poderia perfeitamente ser ministrada por seus assistentes, quando a ele deveriam ser reservados cursos de especialização e orientaçáo em pesquisa.

Ao chegar ao Brasil, Marcus recebeu do professor Paulo Sawaya, que ficara na regência interina da disciplina, dois frascos contendo briozoários e dois exemplares de onicóforos. Foi com esse material que Marcus iniciou a sua magnífica série de trabalhos realizados no Brasil. Em princípio, sua pesquisas realizavam-se com animais marinhos que os Marcus coletavam em excursóes ao litoral ou que recebiam de colegas do resto do país e do exterior. Posteriormente, durante a Segunda Guerra Mundial, por serem ainda alemáes, foram proibidos de ir ao 
litoral. Entấo, passaram a excursionar nos arredores de São Paulo, coletando nos campos e pequenos cursos d'água, animais característicos desses biótopos e, assim, prosseguindo no trabalho. Numa dessas excursóes, o estranho casal, fuçando matas e riachos à cata de bichinhos desconhecidos para o leigo, despertou a atençáo da ronda policial, que chegou a prendê-los transitoriamente.

Como resultado dessas coletas, observaçóes de campo e com paciente trabalho de laboratório, o casal Marcus publicou no Brasil, entre 1936 e 1968, cerca de 162 artigós. Como homenagem ao Brasil, os

Ernest Marcus

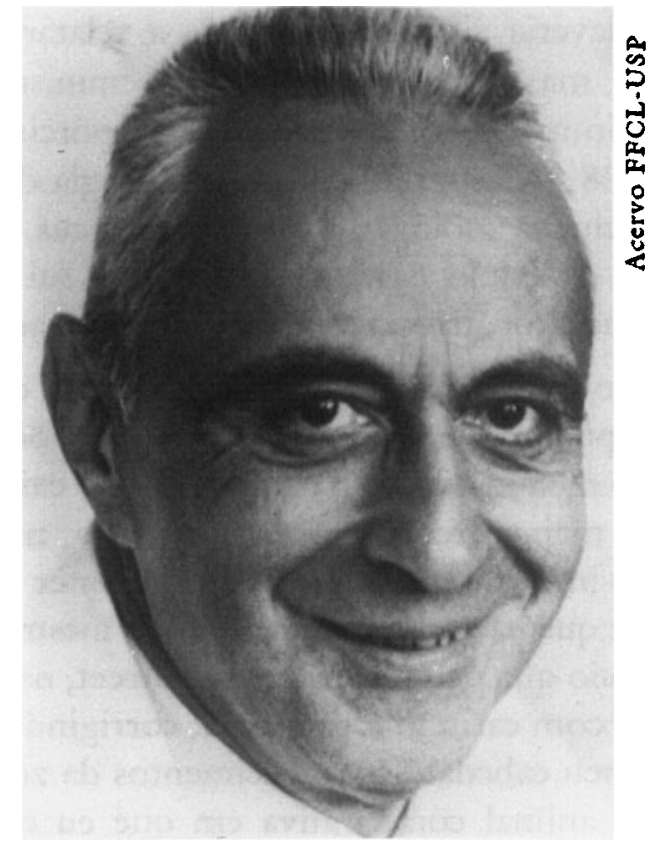

primeiros trabalhos saíram em portuguề, no Boletim de Zoologia da Faculdade de Filosofia. Os seguintes começaram a ser enviados a revistas especializadas no exterior e versaram sobre variados grupos animais (turbelários, poliquetos, oligoquetos, tardígrados, onicóforos, pantópodos, nemertinos, foronídeos, gastrópodes). Os animais eram sempre estudados de múltiplos pontos de vista (sistemático, zoogeográfico, anatômico, embriológico e ecológico). Tiveram sempre grande repercussão, tornando Marcus um dos mais proeminentes zoólogos deste século. A grande zoóloga Libbie $\mathrm{H}$. Hyman aprendeu português para ler os primeiros trabalhos de Marcus e, quando escreveu o tomo sobre briozoários no seu monumental tratado (The Invertebrates), veio a São Paulo para uma temporada com o famoso especialista. 
Ao lado desses trabalhos de cunho especializado, Marcus sempre cultivou, à maneira de Lamarck, a sua filosofia zoologica, publicando ensaios sobre questóes fundamentais dessa disciplina biológica. Seus primeiros trabalhos no Brasil, em português, foram para a revista do Grêmio da Faculdade de Filosofia da USP: Por que estudamos Zoologia, de 36 e Sobre o Sistema Zoológico, de 38. Este último foi refundido e atualizado em 1958; vertido para o inglês, apareceu como $O n$ the Evolution of Animal Phyla, no Quarterly Review of Biology (v.33:24-58), com larga repercussão. No seu Dynamics in Metazoan Evolution (Clarendon, 1964), Clark escolheu trés arpores filogenéticas para comentar e ilustrar o texto, uma delas a proposta por Marcus no artigo de 58.

Haveria ainda muito mais a relatar sobre a obra zoológica de Marcus, mas prefiro concluir esta reminiscência do grande mestre, reportando-me ao convívio que me proporcionou durante quase 32 anos. Em 1938, o Departamento de Zoologia da Faculdade de Filosofia da USP incluía a zoologia, a cargo de Marcus, e a fisiologia geral e animal, a cargo de Paulo Sawaya. Nesse ano, fui admitido no mesmo como aluno-monitor, passando a conviver com ambos os mestres.

Ao me formar, Sawaya tomou-me como seu assistente, pois já havia optado pela disciplina fisiológica. Sempre fui mau desenhista e antevi o meu insucesso na zoologia, que exige tal habilidade; ademais, a função, menos freqüentemente a forma, me seduzia em biologia. Mas isso náo impediu que continuasse a manter estreito contato com Marcus uma vez que na época ele partilhava o mesmo espaço físico com Sawaya, no edifício que pertencera a Jorge Street, na alameda Glette. Sempre me acolheu com carinho e paciência, corrigindo as minhas falhas e aumentando meu cabedal de conhecimentos da zoologia, tão necessários à fisiologia animal comparativa em que eu começava a pesquisar. Esses contatos se intensificaram e acabaram por motivar idas costumeiras à própria casa dos Marcus para, além de conversas, saborear as iguarias alemães que $\mathrm{D}$. Eveline preparava.

Recordo-me bem do dia em que, tendo sido proposto para monitor, os Marcus me convidaram pela primeira vez para um chá em sua residência. Foi na semana do Anschluss da Áustria pelo Nazismo e a conversa rumou para a política internacional e a história da velha Europa. Marcus, entáo, me encantou com seus conhecimentos históricos e políticos. Com o tempo fui me dando conta de que também em outros ramos do saber ele se excedia. Como eu me interessava por literatura e filosofia alemás, ele foi meu professor nessas matérias e pôs-me a par da cultura que florescera no seu país de origem até a queda do império em 1918. Tinha nostalgia da monarquia e da Berlim de seu tempo. 
Sua esposa, D. Eveline, continuou a pesquisar depois da morte de Marcus (30 de junho de 1968). Recebeu o título de Doutor bonoris causa pela USP e foi condecorada pelo governo francês pouco antes de falecer em 1990. Numa visita que o biofísico Keynes (Cambridge) nos fez, manifestou desejo de conhecer D. Eveline. Levei-o, então, a sua sala e Keynes lhe disse: "Dona Eveline, queria conhecê-la pessoalmente porque meu bisavô e o seu avô foram muito amigos". O bisavô de Keynes era Charles Darwin e o avô de Eveline, Du Bois Reymond.

Uns dois anos antes de morrer, Marcus me procurou para dizer que se regozijava "de não me ter tomado como assistente" $e$, ante o meu espanto, completou "porque se o tivesse feito, teríamos os dois passado boa parte desses longos anos conversando em detrimento do meu tempo reservado à pesquisa". Esse episódio diz bem da estreita amizade que nos unia. Marcus e Eveline jazem agora para sempre no Cemitério da Paz, nesta Capital. A rua onde os Marcus moravam ( $R$. Sorocaba) denomina-se hoje R. Ernest Marcus, ligando o Pacaembu à Av. Dr. Arnaldo.

Erasmo Garcia Mendes é professor emérito da USP e integra a Mesa Editorial da revista Estudos Avanfados. 